University of Nebraska - Lincoln

DigitalCommons@University of Nebraska - Lincoln

April 2011

\title{
Grain refinement vs. crystallographic texture: Mechanical anisotropy in a magnesium alloy
}

D. C. Foley

Texas A\&M University

M. Al-Maharbi

Texas A\&M University

K. T. Hartwig

Texas A\&M University, thartwig@tamu.edu

I. Karaman

Texas A\&M University

L. J. Kecskes

US Army Research Lab

See next page for additional authors

Follow this and additional works at: https://digitalcommons.unl.edu/usarmyresearch

Part of the Operations Research, Systems Engineering and Industrial Engineering Commons

Foley, D. C.; Al-Maharbi, M.; Hartwig, K. T.; Karaman, I.; Kecskes, L. J.; and Mathaudhu, S. N., "Grain refinement vs. crystallographic texture: Mechanical anisotropy in a magnesium alloy" (2011). US Army Research. 123.

https://digitalcommons.unl.edu/usarmyresearch/123

This Article is brought to you for free and open access by the U.S. Department of Defense at DigitalCommons@University of Nebraska - Lincoln. It has been accepted for inclusion in US Army Research by an authorized administrator of DigitalCommons@University of Nebraska - Lincoln. 


\section{Authors}

D. C. Foley, M. Al-Maharbi, K. T. Hartwig, I. Karaman, L. J. Kecskes, and S. N. Mathaudhu 


\title{
Grain refinement vs. crystallographic texture: Mechanical anisotropy in a magnesium alloy
}

\author{
D.C. Foley, ${ }^{a}$ M. Al-Maharbi, ${ }^{a}, 1$ K.T. Hartwig, ${ }^{a, b, *}$ I. Karaman, ${ }^{a, b}$ \\ L.J. Kecskes ${ }^{\mathrm{c}}$ and S.N. Mathaudhu ${ }^{\mathrm{c}}$ \\ ${ }^{a}$ Materials Science and Engineering Program, Texas A\&M University, College Station, TX 77843, USA \\ ${ }^{\mathrm{b}}$ Department of Mechanical Engineering, Texas A\&M University, College Station, TX 77843, USA \\ ${ }^{\mathrm{c}}$ US Army Research Lab., Weapons and Materials Research Directorate, Aberdeen Proving Ground, MD 21005, USA
}

Received 31 August 2010; accepted 23 September 2010

Available online 29 September 2010

\begin{abstract}
A magnesium alloy was subjected to severe plastic deformation via an unconventional equal channel angular extrusion route at decreasing temperatures. This method facilitates incremental grain refinement and enhances formability by activating dynamic recrystallization in the initial steps and suppressing deformation twinning. Compression experiments in three orthogonal directions demonstrated high strength levels in the processed sample, up to $350 \mathrm{MPa}$ in yield and $500 \mathrm{MPa}$ in ultimate strengths. Notable flow stress anisotropy is correlated with the processing texture and microstructure.

(C) 2010 Published by Elsevier Ltd. on behalf of Acta Materialia Inc.
\end{abstract}

Keywords: Equal channel angular extrusion/pressing; Magnesium alloys; Ultrafine-grained materials; Anisotropy; Crystallographic texture

Renewed interest in $\mathrm{Mg}$ alloys has generated a wealth of investigations on improving the suitability of these materials for high specific strength applications. Although there are many promising developments in new alloy design [1-3], improvements to conventional alloys by various thermo-mechanical processing methods have been the focus of several recent studies [4-7].

One of these techniques, equal channel angular extrusion (ECAE), has been used to study the effects of severe plastic deformation (SPD) on $\mathrm{Mg}$ alloys with the intent of improving mechanical performance $[4,5,8,9]$. Several groups have achieved significant increases in strength and ductility in $\mathrm{Mg}$ alloys using ECAE [8,9]. The most striking report, by Ding et al. [8], revealed a tensile yield strength of $372 \mathrm{MPa}$ and an ultimate tensile strength of $445 \mathrm{MPa}$ using a multi-temperature hybrid ECAE processing route on AZ31 Mg alloy. Unfortunately, they did not present their rationale for choosing specific temperatures and strain paths used to accomplish these strength levels. On the other hand, most reports on ECAE

\footnotetext{
* Corresponding author at: Materials Science and Engineering Program, Texas A\&M University, College Station, TX 77843, USA. Tel.: +1 979693 4102; fax: +1 979845 3081; e-mail: thartwig@tamu.edu

${ }^{1}$ Present address: Department of Mechanical Engineering, Sultan Qaboos University, Muscat, Oman.
}

of $\mathrm{Mg}$ alloys with routes such as $\mathrm{A}, \mathrm{B}_{\mathrm{c}}$ and $\mathrm{C}$ do not exhibit such high strength levels $[7,8,10]$. Some processing conditions have been reported to result in lower postprocessing strength and/or ductility as compared to the starting commercial material [7,10], in spite of the microstructural refinement. These reported performance drops are often related to processing temperatures $\left(200-300^{\circ} \mathrm{C}\right)$ that encourage dynamic recrystallization (DRX) and softening, and changes in the crystallographic texture. The loading direction with respect to the ECAE processing textures can explain the drop in strength observed in uniaxial mechanical testing, due to the large anisotropy in the critical resolved shear stresses of deformation mechanisms in $\mathrm{Mg}$ alloys [11-13]. Unfortunately, with few exceptions (e.g. $[14,15])$, the literature typically presents unidirectional testing of the starting and deformed materials, and in some cases presents no texture data at all. Biswas et al. [11] were able to ECAE process crackfree pure $\mathrm{Mg}$ at room temperature via route $\mathrm{A}$, generating a fine grain size but with no mechanical data.

Due to the scarcity of multi-directional mechanical testing on SPD-processed Mg alloys, the effect of microstructural refinement on mechanical properties and flow anisotropy is often confounded by texture effects. The crystallographic textures of starting and as-processed materials are usually significantly different and the 
mechanical properties of $\mathrm{Mg}$ alloys are highly anisotropic. Although this is well known, the scale of most research-level ECAE tooling limits the extraction of conventionally sized ASTM tensile specimens solely to the long axis of the processed billets. However, compression testing can be easily carried out on samples of smaller geometry. The current work utilizes compression testing along three orthogonal directions for better understanding and separate the effects of microstructural refinement and changes to texture in AZ31B.

The material in this study underwent processing similar to the study by Ding et al. [8] and Biswas et al. [11]. Ding et al. report that extrusions were carried out in a $120^{\circ}$ angle ECAE tool at several temperatures, starting with $200{ }^{\circ} \mathrm{C}$ and ending at $115^{\circ} \mathrm{C}$. Biswas et al. extruded their material in a $90^{\circ}$ ECAE tool with the first four route A passes being performed at $250^{\circ} \mathrm{C}$, followed by a progressive scaling down of temperature, ending at room temperature on the eighth pass. We have previously used a similar temperature step-down method to SPD process difficult-to-work materials and others have also used a multi-temperature approach in $\mathrm{Mg}$ alloys [10]. The temperature step-down method results in an incremental grain refinement by both DRX at higher temperatures $[11,16]$ and conventional defect accumulation throughout the temperature range [11]. This method enables uniform grain refinement at higher temperatures with the help of DRX. Lower temperature processing benefits from more involvement of grain boundary mediated mechanisms in deformation, suppressing the shear localization or cracking that often occurs in $\mathrm{Mg}$ alloys processed at a single low temperature. The present study evaluates the effectiveness of temperature stepdown processing and investigates the multi-directional mechanical behavior of both starting and processed materials with an effort to separate the effects of texture and microstructural refinement.

A commercial AZ31B hot-rolled plate was used for this study. The plate was annealed at $350{ }^{\circ} \mathrm{C}$ for $12 \mathrm{~h}$, which is hereafter referred to as the reference (REF) condition. The following ECAE procedure was undertaken in a $25 \times 25 \mathrm{~mm}$ cross-section, $90^{\circ}$ ECAE tool with sharp corners and sliding walls: two extrusion passes using route $\mathrm{A}$ (no rotation between passes, $2 \mathrm{~A}$ ) at $200{ }^{\circ} \mathrm{C}$ with an extrusion speed of $2.5 \mathrm{~mm} \mathrm{~s}^{-1}$, a $180^{\circ}$ rotation around the billet's long axis, another $2 \mathrm{~A}$ at $150^{\circ} \mathrm{C}$ with an extrusion speed of $0.75 \mathrm{~mm} \mathrm{~s}^{-1}$, another $180^{\circ}$ rotation and one pass at $125^{\circ} \mathrm{C}$ with an extrusion speed of $0.25 \mathrm{~mm} \mathrm{~s}^{-1}$. This sequence is identified in this work as $5 \mathrm{H}$, as it is a five-step hybrid route. This was inspired by the route reported in Ref. [8]. The extrusion rates were chosen to prevent shear localization. A backpressure of $30 \mathrm{MPa}$ was applied during extrusions to increase the hydrostatic stress at the shear zone. The relatively low friction of the sliding wall ECAE die used here results in lower inherent hydrostatic stress at the shear zone compared to a conventional "clamshell" ECAE die. Low hydrostatic stress is detrimental to strain uniformity, so a backpressure was applied to suppress shear band formation [17]. Unfortunately, the short exit channel of this tool prevents the use of significant backpressure in relatively weak materials like $\mathrm{Mg}$ alloys. The solution was to encapsulate the sample in an interstitial-free steel can of $3 \mathrm{~mm}$ wall thickness. This arrangement allowed for the application of $30 \mathrm{MPa}$ backpressure. Conventional ECAE tooling should allow replication of this study without encapsulation and possibly without backpressure.

Compression samples were wire electro discharge machined from the REF and 5H billets in three orthogonal directions. Optical microscopy samples were prepared via mechanical polishing followed by a two-step etching process [12]. A Keyence VHX 600 microscope was used to collect optical micrographs. The crystallographic texture was measured on the rolling plane of the REF material and the flow plane (normal to the flow direction (FD) defined in Fig. 1) of the $5 \mathrm{H}$ material using a Bruker D8 Discover diffractometer with $\mathrm{Cu} K_{\alpha}$ radiation. Compression samples with dimensions of $4 \times 4 \times 8 \mathrm{~mm}^{3}$ were tested at room temperature using an MTS load frame. A miniature extensometer with a $3 \mathrm{~mm}$ gauge length directly attached to the samples was used to measure strain. The compression samples from $5 \mathrm{H}$ were cut along the extrusion direction (ED), FD and longitudinal direction (LD) of the billet, as shown in Figure 1. The REF compression samples were cut from the through-thickness (TT), rolling and transverse directions. The latter two have essentially the same behavior, so the results from only one are presented here as the in-plane (IP) direction.

The REF material consists of equiaxed grains with an average size of $25 \mu \mathrm{m}$ and a typical range of $10-70 \mu \mathrm{m}$, shown in Figure 2a. The texture of the REF material is shown in Figure $3 a$ with a $\left\langle\begin{array}{llll}0 & 0 & 0 & 2\end{array}\right\rangle$ pole figure. The basal poles are oriented primarily normal to the plate surface as expected for a hot-rolled $\mathrm{Mg}$ alloy. The ECAE processing was carried out by orienting the basal poles (plate normal) parallel to the exit channel/extrusion direction on initial insertion into the ECAE die, as shown in Figure 1. This puts the basal planes at approximately $45^{\circ}$ from the shear zone plane and results in a deformation mode dominated by basal slip [12,13].

After a single pass at $200{ }^{\circ} \mathrm{C}$, the microstructure appears as in Figure 2b. Significant refinement has occurred through DRX, but large regions still exists that may have undergone significant deformation but remain unrefined. Additional extrusions at $200{ }^{\circ} \mathrm{C}$ (strains of 4 or more) satisfactorily eliminate the unrefined regions with further

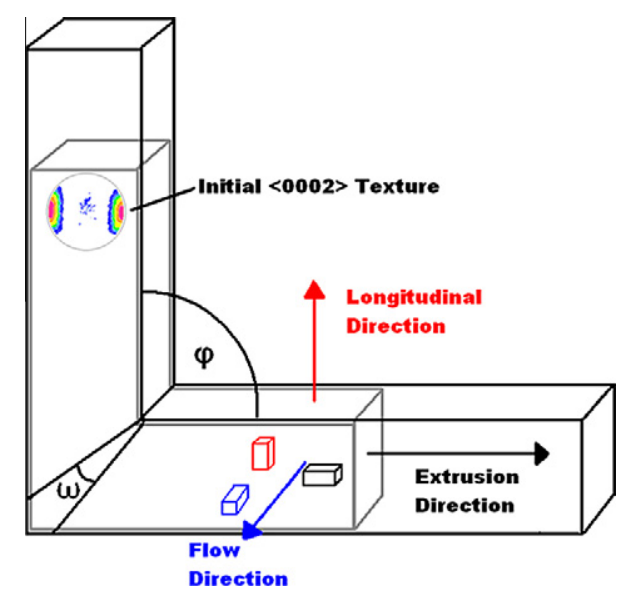

Figure 1. Initial texture of the AZ31B Mg alloy as the billet enters the tool in the first pass and orientations of compression samples. 


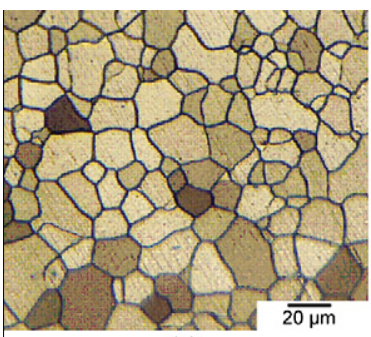

(a)

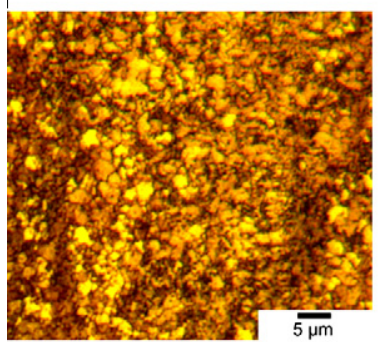

(c)

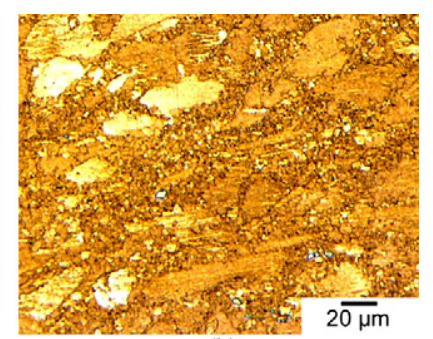

(b)

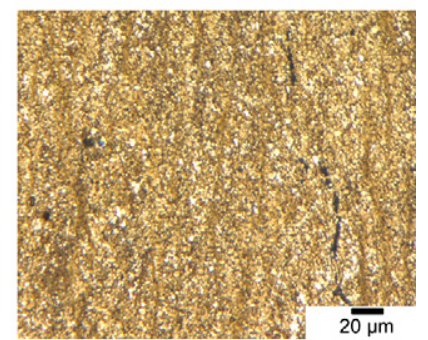

(d)
Figure 2. Optical micrographs of (a) the hot-rolled and annealed AZ31B Mg alloy taken on the rolling plane, (b) the sample after one pass at $200{ }^{\circ} \mathrm{C}$ recorded on the flow plane, (c) ECAE 5H sample taken on the longitudinal plane and (d) the same sample at a lower magnification.

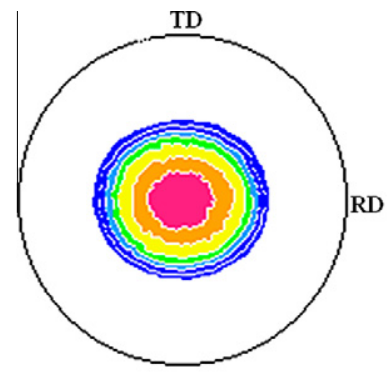

(a)

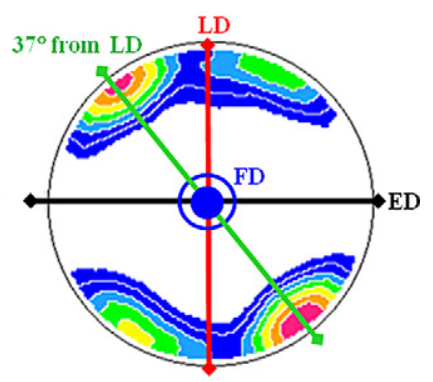

(b)
Figure 3. $\left\langle\begin{array}{llll}0 & 0 & 0 & 2\end{array}\right\rangle$ pole figures for (a) the hot-rolled and annealed AZ31B Mg alloy (REF) recorded on the rolling plane and (b) the ECAE processed sample $(5 \mathrm{H})$ taken on the flow plane (see Fig. 1). Directional arrow colors correspond with the orientations in Figure 1 and compression curves in Figure 4. FD, flow direction; LD, longitudinal direction; ED, extrusion direction.

DRX, resulting in a uniform grain size of 3-5 $\mu \mathrm{m}$ (not shown here) $[12,13,18]$. On the other hand, the decreasing processing temperatures in route $5 \mathrm{H}$ result in an optically visible grain size of $1-4 \mu \mathrm{m}$, as shown in Figure 2c. Note the dark regions in this figure; Figure $2 \mathrm{~d}$ is at lower magnification and more clearly shows the darker shear bands revealed by etching. These bands are typical for shear localization, as reported by others [17], and likely contain submicron grains.

The order-of-magnitude microstructural refinement in the $5 \mathrm{H}$ billet is accompanied by a significant change in crystallographic texture. The selected route ensures that the evolved texture after each pass does not favor deformation twinning in the following pass, activation of which can result in poor formability $[11,19]$. This is especially important at lower temperatures, at which there is no ductility enhancement from DRX. The incremental grain refinement using the processing temperature step-down method also helped to suppress twinning. Thus, subsequent ECAE passes are accommodated primarily by basal slip with varying amounts of pyramidal $\langle c+a\rangle$ and prismatic slip, as predicted by the visco-plastic self-consistent crystal plasticity simulations [12-13]. The $5 \mathrm{H}$ deformation sequence results in a split basal texture, as shown in Figure $3 \mathrm{~b}$, with a highintensity basal peak oriented $\sim 37^{\circ} \mathrm{CCW}$ from the vertical, i.e. LD in Figure 1, and a secondary peak oriented $\sim 30^{\circ} \mathrm{CW}$. This texture will be shown to govern the mechanical response of the $5 \mathrm{H}$ sample; colored arrows over the pole figure are placed to aid the reader in correlating the mechanical response curves in Figure 4 with their orientations in Figure 3.

The compression stress-strain responses of the REF and 5H samples are presented in Figure 4. In both cases, the texture-driven anisotropy is obvious. However, it is also clear that the refined microstructure of $5 \mathrm{H}$ results in significantly higher strength levels. From the textures in Figure 3, there are two roughly comparable cases between the two materials. First, the compression responses along the FD direction in the 5H sample and along the IP direction in the REF sample both show the characteristic of twinning-dominated deformation: a low or no-hardening plateau region in the first stage followed by an upward stress-strain curve in the second stage [20]. The yield strength in this deformation mode responds dramatically to grain refinement, as the $5 \mathrm{H}$ sample yields along the FD direction at almost four times the strength level and ultimate strength goes to over $500 \mathrm{MPa}$, as compared to nearly $300 \mathrm{MPa}$ for the IP direction of the REF plate. The second set of readily comparable samples is the REF compressed along the TT direction vs. $5 \mathrm{H}$ material compressed along the direction called $37^{\circ}$, as both are parallel to the basal poles. Twinning should not play a major role here, thus the stress-strain response follows a downward curve in the REF sample along the TT direction. The much higher yield strength in the $5 \mathrm{H} 37^{\circ}$ sample comes at the cost of ductility, as the samples exhibited almost no plasticity. The 5H LD samples also had less ductility than expected.

The material here was processed using a hybrid route, where route $\mathrm{A}$ was interrupted by a $180^{\circ}$ rotation between temperature steps. Although Ding et al. [8] stated that this was necessary to avoid billet cracking, the

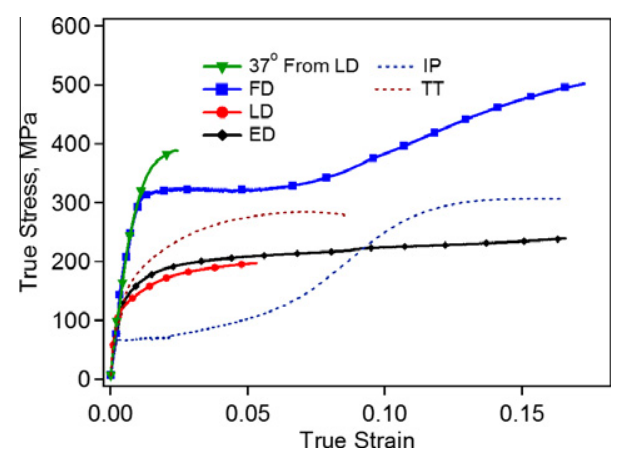

Figure 4. Compressive stress-strain response of AZ31B Mg alloy for the hot-rolled and annealed samples along two directions and for the ECAE processed $5 \mathrm{H}$ samples along four directions. $37^{\circ}$, the sample in the direction of the strongest basal pole intensity (Fig. 3b); IP, in-plane direction of the plate; TT, through-thickness direction of the plate. 
authors did not observe this phenomenon in other similar extrusions. However, 5A would result in a substantial macroscopic strain disparity throughout the billet (low product yield with uniform deformation) [21]. What may be more important about the strain path selection is the preferential hardening of basal slip and the suppression of twinning. The strength disparity between basal slip and non-basal slip systems is a significant factor in shear localization. By using progressively lower temperatures and strain paths that encourage basal slip activity, the strong anisotropy in the critical shear stresses of basal and non-basal slip may be reduced. Ideally, this should lead to more uniform deformation and explains the successful processing at temperatures below the $200{ }^{\circ} \mathrm{C}$ level, as recently reported by a number of groups $[8,11]$.

The differences in formability, when comparing this work to the Ding et al. example, can be partially attributed to backpressure and partially to the differing texture changes imparted by extrusions through a $120^{\circ}$ die vs. a $90^{\circ}$ ECAE die. However, we have found that decreasing punch speed with temperature is one of the keys to taking advantage of diffusion-driven deformation, suppressing shear localization. Without this decrease in punch speed, the workpiece must increasingly rely on twinning to accommodate $\langle c+a\rangle$ deformation at the lower temperatures, which may cause shear localization/failure due to stress concentration at the twin tips $[19,22]$. Finally, it is important to note that the initial workpiece texture and the route A processing at $200{ }^{\circ} \mathrm{C}$ suppress prismatic slip and encourage DRX, generating a finer and more uniform microstructure than the starting material $[12,13]$. This encourages more homogeneous deformation at lower temperatures.

In summary, the present work clearly points out that understanding the interplay between crystallographic texture evolution and active deformation mechanisms in the presence of microstructural refinement is crucial to the development of hybrid SPD processing routes for $\mathrm{Mg}$ alloys. By developing a comprehensive understanding of this interplay, well-designed SPD processing will ultimately result in uniform, highly refined microstructures and very high specific strength levels.

The key findings of this study are as follows:

- SPD processing using a decreasing temperature (stepdown) approach is an effective method for grain refinement in AZ31B Mg alloy.

- Step-down ECAE processing resulted in a compressive yield stress as high as $350 \mathrm{MPa}$ and an ultimate stress as high as $500 \mathrm{MPa}$ with $18 \%$ ductility.
- Texture effects dominate the mechanical properties. Strength enhancement with a corresponding increase in ductility can be obtained through a combination of grain refinement and texture control.

This work was funded by the US Army Research Laboratory through contract W911QX-08-P0640. The authors acknowledge the important assistance of R. Barber and D. Krebs for ECAE processing.

[1] T. Homma, N. Kunito, S. Kamado, Scripta Mater. 61 (2009) 644.

[2] C.I. Mendis, K. Oh-ishi, K. Hono, Scripta Mater. 57 (2007) 485.

[3] B.I. Bonderov, T.M. Kunyavskaya, E.V. Ehina, J.S. Korivera, in: B.L Mordike, F. Hehmann (Eds.), Magnesium Alloys and their Applications. DGM, GarmishParken Kirchen, Germany, 1992, pp. 237-241.

[4] A. Yamashita, Z. Horita, T.G. Langdon, Mat. Sci. Eng A 300 (2001) 142.

[5] S.R. Agnew, P. Mehrotra, T.M. Lillo, G.M. Stoica, P.K. Liaw, Mat. Sci. Eng A 408 (2005) 72.

[6] S. Suwas, G. Gottstein, R. Kumar, Mat. Sci. Eng A 471 (2007) 1 .

[7] T. Mukai, M. Yamanoi, H. Watanabe, K. Higashi, Scripta Mater. 45 (2001) 89.

[8] S.X. Ding, W.T. Lee, C.P. Chang, L.W. Chang, P.W. Kao, Scripta Mater. 59 (2008) 1006.

[9] B. Chen, D.L. Lin, L. Jin, X.Q. Zeng, C. Lu, Mat. Sci. Eng A 483 (2008) 113.

[10] H.K. Kim, W.J. Kim, Mat. Sci. Eng A 385 (2004) 300.

[11] S. Biswas, S.S. Dhinwal, S. Suwas, Acta Mater. 58 (2010) 3247.

[12] M. Al-Maharbi, D. Foley, I. Karaman, I. Beyerlein, K.T. Hartwig, L. Kecskes, S. Mathaudhu, Magnesium Technology 2010, TMS Warrendale, PA, USA, 2010, p. 445.

[13] M. Al-Maharbi, PhD dissertation, Texas A\&M University, 2009.

[14] W.J. Kim, J.B. Lee, W.Y. Kim, H.T. Jeong, H.G. Jeong, Scripta Mater. 56 (2007) 309.

[15] S.R. Agnew, O. Duygulu, Int. J. Plast 21 (2005) 1161.

[16] J.C. Tan, M.J. Tan, Mat. Sci. Eng A 339 (2003) 124.

[17] R. Lapovok, D. Hodgson, J. Mech Phys Solids 57 (2009) 1851.

[18] R.B. Figueiredo, T.G. Langdon, Mat. Sci. Eng A 430 (2006) 151.

[19] M.R. Barnett, Mat. Sci. Eng A 464 (2007) 8.

[20] D.W. Brown, S.R. Agnew, M.A.M. Bourke, T.M. Holden, S.C. Vogel, C.N. Tomé, Mat. Sci. Eng A 399 (2005) 1.

[21] R. Barber, T. Dudo, P. Yasskin, K.T. Hartwig, Scripta Mater. 51 (2004) 373.

[22] Y.J. Li, Y.J. Chen, J.C. Walmsley, R.H. Mathinsen, S. Dumoulin, H.J. Roven, Scripta Mater. 62 (2010) 443. 